\title{
Transplantation of Normal Bone Marrow into a Pig with Severe von Willebrand's Disease
}

\author{
E. J. W. Bowie, L. A. Solberg, Jr., D. N. Fass, C. M. Johnson, G. J. Knutson, M. L. Stewart, and L. J. Zoecklein \\ Department of Hematology Research, Mayo Clinic, Rochester, Minnesota 55905
}

\begin{abstract}
Bone marrow from a normal male pig was transplanted into a related female pig with severe homozygous von Willebrand's disease (vWd). After engraftment the circulating leukocytes were of the male karyotype, and the platelets were strongly positive for von Willebrand factor (vWF) by indirect immunofluorescence. The average level of vWF was $1.96 \mathrm{U} / \mathrm{dl}$ and of ristocetin cofactor was $2.8 \mathrm{U} / \mathrm{dl}$. The ear immersion bleeding time before transplantation was consistently more than $15 \mathrm{~min}$ and afterwards varied between $5 \mathrm{~min}$ and more than $15 \mathrm{~min}$. Transfused vWF corrected the bleeding time at a level of $10 \mathrm{U} / \mathrm{dl}$, which is lower than that required for a von Willebrand pig. We concluded that: (a) the plasmatic compartment is only minimally replenished by the vWF from platelets and megakaryocytes; and $(b)$ the platelet vWF alone only partially corrects the abnormal tests of the hemostatic mechanism in severe $\mathrm{vWd}$.
\end{abstract}

\section{Introduction}

Von Willebrand factor (vWF $)^{1}$ is a large adhesive protein which plays an important role in the interaction of the platelet and the blood vessel. It circulates in the plasma as a series of high molecular weight polymers (1-4). The protein is present in the platelet megakaryocyte and endothelial cell as well as in the plasmatic compartment and has also been shown to be located subendothelially in the blood vessels $(5,6)$. It appears to be synthesized in human endothelial cells (7-9) and the megakaryocyte (10). In the pig, vWF has been identified in the same locations as in humans $(11,12)$. In humans the protein is found both in the platelet alpha granule and in the platelet membrane (13-16) and can be released from the platelet by collagen, thrombin, and ADP (15-18). In cultures of human endothelial cells, vWF can be released by epinephrine but not by 1-desamino-8-D-arginine-vasopressin (DDAVP) $(5,6)$.

The relative contributions to hemostasis of vWF synthesized by the megakaryocytes and by the endothelial cells are unknown. Availability of pigs with von Willebrand's disease ( $\mathrm{vWd}$ ) allowed us to approach this question through bone marrow transplantation. We transplanted marrow of a normal male pig into a related female pig with severe homozygous vWd so that engraft-

Address reprint requests to Dr. Bowie, Department of Internal Medicine, Division of Hematology, Mayo Clinic, Rochester, MN 55905.

Received for publication 27 January 1986

1. Abbreviations used in this paper: DDAVP, 1-desamino-8-D-argininevasopressin; MLC, mixed lymphocyte cultures; PPP, platelet-poor plasma; RCof, ristocetin cofactor; vWd, von Willebrand disease; vWf, von Willebrand factor; vWf:Ag, von Willebrand antigen.

J. Clin. Invest.

(c) The American Society for Clinical Investigation, Inc.

0021-9738/86/07/0026/05 \$1.00

Volume 78, July 1986, 26-30 ment could be confirmed by examination of the karyotype. This is the first time such an experiment has been performed and we report here the results of these studies.

\section{Methods}

Von Willebrand pig colony. For several years we have maintained a breeding colony of pigs with vWd (19). These animals have the impairment of primary hemostasis and other hemostatic abnormalities of the severe form of the disease in humans $(20,21)$. The animals have a serious bleeding tendency $(19,22)$, which is transmitted as an autosomal recessive characteristic $(23,24)$. The abnormal tests of hemostasis include prolongation of the bleeding time, reduced platelet retention, almost complete absence of von Willebrand antigen (vWF:Ag) $(0.09$ to $0.48 \mathrm{U} / \mathrm{dl}$ by immunoradiometric assay), and the lack of ristocetin cofactor $(\mathrm{RCoF})$ in the plasma.

Nomenclature of Factor VIII and vWF. Factor VIII is the coagulant activity which is absent or abnormal in hemophilic plasma; antihemophilic factor. It is measured by the degree of correction of clotting of the human hemophilia A plasma in the activated partial thromboplastin time (25). Values above $1 \mathrm{U} / \mathrm{dl}$ of normal can be reliably measured for this factor; $1 \mathrm{U}$ of pig Factor VIII activity is equivalent to $\sim 8 \mathrm{U}$ of human Factor VIII (19).

vWF is the activity necessary for the formation of the platelet plug. The antigenic determinants of vWF were detected by rabbit antibodies to purified vWF (26) measured by electroimmunoassay (27). The assay is calibrated to a low limit of $3 \mathrm{U} / \mathrm{dl}$. The vWF:Ag was also measured by a previously described immunoradiometric assay, which is sensitive to a lower limit of $0.005 \mathrm{U} / \mathrm{ml}(28)$.

The RCoF refers to the plasmatic activity that allows ristocetin to induce platelet agglutination. This activity is measured by the degree of agglutination of washed, gel-filtered human platelets using Olson's modification (29) of Weiss' method (30). The standard curve for this assay extends from $6.25 \mathrm{U} / \mathrm{dl}$ to $50 \mathrm{U} / \mathrm{dl}$; values as low as $3 \mathrm{U} / \mathrm{dl}$ were estimated by extrapolation.

Tests of hemostasis. The basic tests of hemostasis in pigs have been described by Bowie et al. $(19,25)$.

Ear immersion bleeding time. The ear immersion bleeding time is measured by Mertz's modification (31) of the immersion method of Doettl and Ripke (32). An incision is made with a No. 11 Bard Parker (Division of Becton-Dickinson \& Co., Rutherford, NJ) blade to a depth of $5 \mathrm{~mm}$. The ear is immediately placed in a beaker containing $50 \mathrm{ml}$ of citrated saline solution that has been warmed to $37^{\circ} \mathrm{C}$, and the time of bleeding is measured. The ear immersion bleeding time is an extremely reproducible test. The mean was $2.2 \mathrm{~min}( \pm 0.75 \mathrm{SD} ; 595$ observations in 257 normal pigs).

Ratio bleeding time (12). The blood loss in the first $3 \mathrm{~min}$ is expressed as a ratio of the blood loss in the next $12 \mathrm{~min}$. The bleeding time incision is made in the pig's ear as described in the above section, and the ear is immersed in a glass beaker containing $100 \mathrm{ml}$ of citrated saline warmed to $37^{\circ} \mathrm{C}$. After $3 \mathrm{~min}$ the beaker is replaced with another beaker containing the same volume of warmed citrated saline, the ear is kept immersed for another $12 \mathrm{~min}$, and the time that bleeding stops is noted. The 12min erythrocyte count is divided by the 3-min erythrocyte count. The quotient is the ratio bleeding time. The ratio bleeding time is relatively independent of the volume of blood loss (12). Normal values are $<0.8$.

Indirect immunofluorescence. The indirect immunofluorescence technique for vWF in tissue sections was performed by the method of Katzmann et al. (28). 
Multimeric distribution. The multimeric distribution of vWF was determined by sodium dodecyl sulfate agarose electrophoresis employing a discontinuous buffer system (33). The stacking and separating gels were $0.8 \%$ and $2 \%$ agarose, respectively. vWF multimers were probed using affinity-purified radiolabeled rabbit antibodies to porcine vWF and were visualized by autoradiography.

Mixed lymphocyte culture. Standard one-way and two-way mixed lymphocyte cultures (MLC) were carried out using techniques essentially identical to those used for human MLC testing (34-36). Donor/recipient pairs who showed mutual nonstimulation in the MLC were chosen for transplantation.

Chromosome analysis. Phytohemagglutinin-stimulated T cells were cultured from peripheral blood. 20 metaphases stained by C-banding were analyzed to establish the presence or absence of a $\mathrm{Y}$ chromosome (37).

Platelet $v W F: A g$. Platelet vWF:Ag was determined using a modification of the method of Gralnick et al. (38). Briefly, citrated plateletrich plasma and platelet-poor plasma (PPP) were prepared by centrifugation at $1,200 \mathrm{~g}$ for $10 \mathrm{~min}$ at room temperature. Platelets were lysed by the addition of $1 / 40 \mathrm{vol} / \mathrm{vol}$ of $20 \%$ Triton X-100; the sample was incubated at $37^{\circ} \mathrm{C}$ for $15 \mathrm{~min}$ and frozen at $-70^{\circ} \mathrm{C}$. Platelet debris was removed from the thawed sample by centrifugation in a microfuge for 10 min. vWF:Ag was assayed by the Laurell technique and platelet vWF: $\mathrm{Ag}$ was determined by subtracting the value for the PPP from that of the lysed sample.

Bone marrow transplantation. A female pig with severe $\mathrm{vWd}$ (Table I) was used as the recipient of the bone marrow transplant. She was 5-mo-old and weighed $69 \mathrm{~kg}$. A Hickman catheter (Evermed, Inc., Kirkland, WA) was placed into the right atrium via the jugular vein on day -10 after the transfusion of 10 bags $(350 \mathrm{ml})$ of porcine cryoprecipitate. The cryoprecipitate transfusion was repeated at $12-\mathrm{h}$ intervals for $2 \mathrm{~d}$.

The pig was irradiated on day 0 with a total dose of 800 centiGray given at 7 centiGray/min from a 4,000,000-electron volt linear accelerator. Cyclophosphamide was not given because it caused severe stomatitis in two previous bone marrow transplantations.

A normal related male pig was used as the donor of the bone marrow. Tests of hemostasis are given in Table I. He was 11-mo-old and weighed $135 \mathrm{~kg}$. The donor pig was anesthetized with ketamine and xylazine. Posterior iliac crest and sternal areas were shaved and cleaned with Betadine. Bone marrow aspirates were obtained from the iliac crest and sternum with Jamshidi needles. The marrow cells were collected into Iscove's modification of Dulbecco's modified Eagle's medium with $2 \mathrm{U} /$ $\mathrm{ml}$ of preservative-free heparin (O'Neill and Co., St. Louis, MO). The bone marrow aspirate was infused over a 3-h period and a total of $10^{9}$ mononuclear cells/ $\mathrm{kg}$ was given. Antibiotic coverage began empirically with amikacin, cefazolin, and mezlocillin. $3 \mathrm{~d}$ later erythromycin was started. On day +5 the pig developed loose brown diarrhea and on the following day biweekly trimethoprim/sulfamethoxazole was initiated. On day +8 , because of persistent low grade fever, amphotericin B was started. Irradiated, compatible, random donor porcine platelets were transfused to keep the platelet count above $20,000 / \mathrm{mm}^{3}$ during the period of engraftment. Irradiated red blood cell transfusions from the donor were given as needed to maintain the hemoglobin at a level $>8 \mathrm{~g} / \mathrm{dl}$. On day +8 , total parenteral nutrition was started.

Table I. Tests of Hemostasis in the Donor and Recipient Pigs

\begin{tabular}{|c|c|c|c|c|c|c|}
\hline & \multirow{2}{*}{$\begin{array}{l}\text { Platelet } \\
\text { count } \\
10^{3} / \mathrm{mm}^{3}\end{array}$} & \multicolumn{2}{|c|}{$\begin{array}{l}\text { Bleeding time } \\
\text { (ear immersion) }\end{array}$} & \multirow{2}{*}{$\begin{array}{l}\text { VIII } \\
\text { Activity }\end{array}$} & \multirow[b]{2}{*}{$\mathrm{RCoF}$} & \multirow[b]{2}{*}{ vWF:Ag } \\
\hline & & Time & Ratio & & & \\
\hline & & $\min$ & & $U / d l$ & $U / d l$ & $U / d l$ \\
\hline Male donor & 500 & 2.3 & 0.008 & 200 & 64 & 65 \\
\hline \multicolumn{7}{|l|}{ Female } \\
\hline recipient & 708 & $15+$ & 13.8 & 44 & $<3$ & $<3$ \\
\hline
\end{tabular}

The pig developed acute graft versus host disease on day +16 with fever and a macular erythematous rash on abdomen, back, and inner ears. Methylprednisolone sodium succinate was started and the skin rash promptly improved. Carnation Instant Breakfast (Carnation Co., Los Angeles, CA) was given for caloric supplementation. On day +32 , oral mycostatin was administered to suppress candidiasis. After engraftment the pig received $20 \mathrm{mg}$ of prednisone twice daily. Thereafter the pig's clinical course was one of steady improvement.

Preparation of partially purified $v W F$. Partially purified porcine vWF was prepared according to the method described by Olson et al. (29). Nine parts normal porcine blood was collected into one part $3.8 \% \mathrm{Na}$ citrate, $0.5 \mathrm{M} \epsilon$-aminocaproic acid, $0.1 \mathrm{M}$ benzamidine, and $5 \mathrm{mg} / 100$ $\mathrm{ml}$ soybean trypsin inhibitor anticoagulant. PPP was prepared by centrifugation at $5,000 \mathrm{~g}$ for $10 \mathrm{~min}$ at $20^{\circ} \mathrm{C}$. Adsorbed plasma was prepared by adsorbing PPP with $10 \%$ (vol/vol) $\mathrm{Al}(\mathrm{OH})_{3}$ for $10 \mathrm{~min}$ at $20^{\circ} \mathrm{C}$ followed by centrifugation at $5,000 \mathrm{~g}$ for $10 \mathrm{~min}$ at $4^{\circ} \mathrm{C}$. Potassium phosphate ( $2 \mathrm{M}, \mathrm{pH}$ 6.5) was added slowly to the adsorbed plasma at $4^{\circ} \mathrm{C}$ until the solution was $0.95 \mathrm{M}$ with respect to potassium phosphate. After gentle stirring for $1 \mathrm{~h}$, the suspension was centrifuged at $5,000 \mathrm{~g}$ for $10 \mathrm{~min}$ at $4^{\circ} \mathrm{C}$. The precipitate was dissolved in a buffer of $0.02 \mathrm{M} \mathrm{Na}$ citrate and $0.14 \mathrm{M} \mathrm{NaCl}, \mathrm{pH} 7.4$, so that the final volume was $7.8 \%$ of the starting plasma volume. The protein solution was then dialyzed at $4^{\circ} \mathrm{C}$ vs. 10 vol of the same buffer (total of three changes at 2-h intervals). The final volume of the partially purified vWF was $9-10 \%$ of the starting plasma volume with a concentration of $10-15 \mathrm{U} / \mathrm{ml}$ ristocetin activity and 6$10 \mathrm{U} / \mathrm{ml}$ antigen.

Cryoprecipitate was made from normal pig plasma by the method of Slichter et al. (39).

\section{Results}

The tests of hemostasis performed in the female pig with severe $\mathrm{vWd}$ and the normal related male are shown in Table I. The course of engraftment for the first $6 \mathrm{wk}$ is shown in Fig. 1. Proof of engraftment was indicated by the fact that the peripheral blood lymphocytes were of the male karyotype. The platelet count rose rapidly $3 \mathrm{wk}$ after transplantation and by $4 \mathrm{wk}$ the platelet count and white count were normal; subsequently the hemoglobin became normal.

Endothelial cell $v W F$. Skin biopsies were obtained at weekly or biweekly intervals and no vWF could be found in the endothelial cells by immunofluorescence.

Tests of hemostasis. The data will be given for the period between $6 \mathrm{wk}$ and $19 \mathrm{wk}$ after the marrow transplantation; during this time the pig did not receive transfusions nor was it subjected to any other investigational procedure.

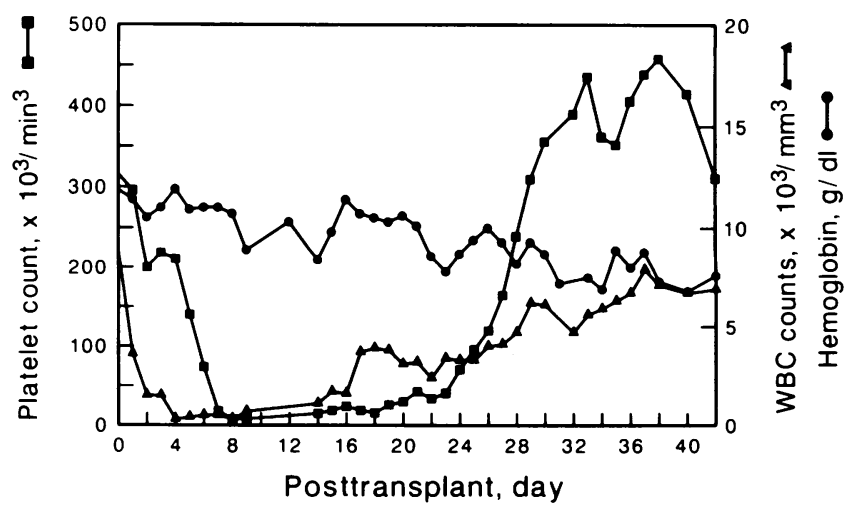

Figure 1. The levels of hemoglobin, leukocytes, and platelets in the blood after the transplantation of normal porcine bone marrow into a pig with severe $v W d$. 
Bleeding time. The ear immersion bleeding time was consistently $>15 \mathrm{~min}$ before the transplantation (normal, $2.2 \pm 0.75$ $\mathrm{min}$ ), and the ratio bleeding time measured 13.8 (normal, <0.8). After engraftment the ear immersion bleeding time varied between $4 \mathrm{~min}$ and $33 \mathrm{~s}$ and more than $15 \mathrm{~min}$. The ratio bleeding time varied between 0.06 and 12.6 , with an average of 3.4.

Factor VIII, vWF:Ag, and RCoF. The levels of Factor VIII fluctuated from 20 to $50 \mathrm{U} / \mathrm{dl}$. In 57 samples on different days, the mean value for the vWF:Ag by Laurell was $1.96 \mathrm{U} / \mathrm{dl}$ (range, 0-6.5) and was $4.6 \mathrm{U} / \mathrm{dl}$ by immunoradiometric assay (range, 1.7-10.3). In 56 samples the RCoF gave a mean value of 2.8 $\mathrm{U} / \mathrm{dl}$ (range, 0-10). The samples included were all taken on different days at times when the pig was quiescent and had not recently been transfused or subjected to any other procedure. Fig. 2 shows the values of Factor VIII and vWF:Ag from day 41 to 70 .

When the plasma was centrifuged so that it was platelet-free $(12,000 \mathrm{~g}$ for $5 \mathrm{~min}$ at room temperature) the level of $\mathrm{vWF}: \mathrm{Ag}$ and RCoF were not reduced.

Platelet and endothelial cells. Before the bone marrow transplantation neither the platelets nor the endothelial cells of the recipient von Willebrand pig contained vWF demonstrable by immunofluorescence. $18 \mathrm{wk}$ after transplantation no vWF was evident in the endothelial cells.

4 wk after transplantation occasional platelets became positive for vWF and by $6 \mathrm{wk}$ all the circulating platelets were strongly positive by immunofluorescence. The platelet transfusions had been discontinued on day +11 . Sodium dodecyl sulfate gel electrophoresis showed that the distribution of vWF polymers in the platelet was normal (Fig. 3).

The platelet content of vWF:Ag was normal, measuring 0.88 $\mathrm{U} / 10^{9}$ platelets in the transfused pig and averaging $1.13 \mathrm{U} / 10^{9}$ platelets in three normal pigs.

Transfusion of $v W F$. In previous experiments (19) we have shown that the transfusion of a partially purified preparation of $\mathrm{vWF}$ or of pig cryoprecipitate into a pig with $\mathrm{vWd}$ will result in correction of the ear immersion bleeding time when the plasmatic level of vWF:Ag and RCoF are $\sim 40 \mathrm{U} / \mathrm{dl}$. The pig with vWd has no vWF:Ag detectable by immunofluorescence in the platelet or endothelial cells and none was detected in these structures after the transfusion of vWF (19).

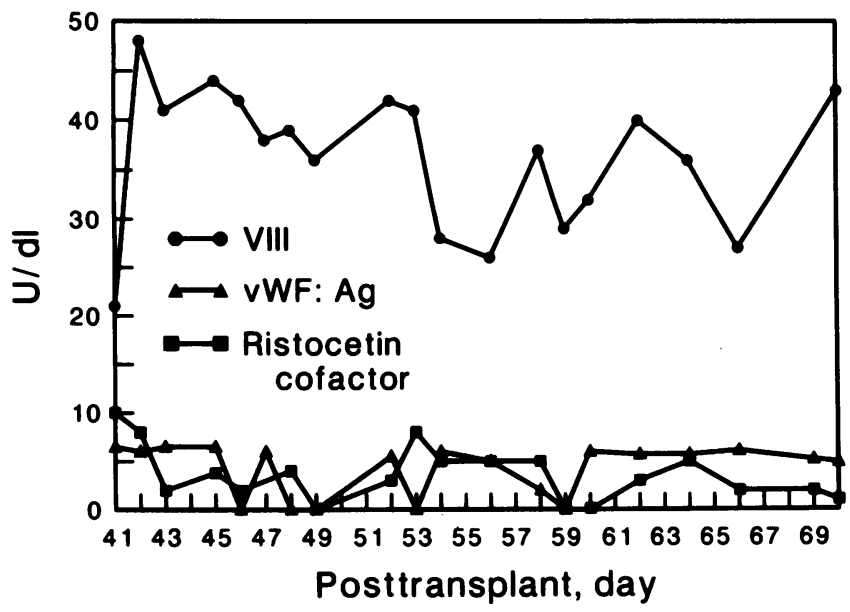

Figure 2. The level of Factor VIII, vWF:Ag, and RCoF during a quiescent period after engraftment of the normal porcine bone marrow transplant.

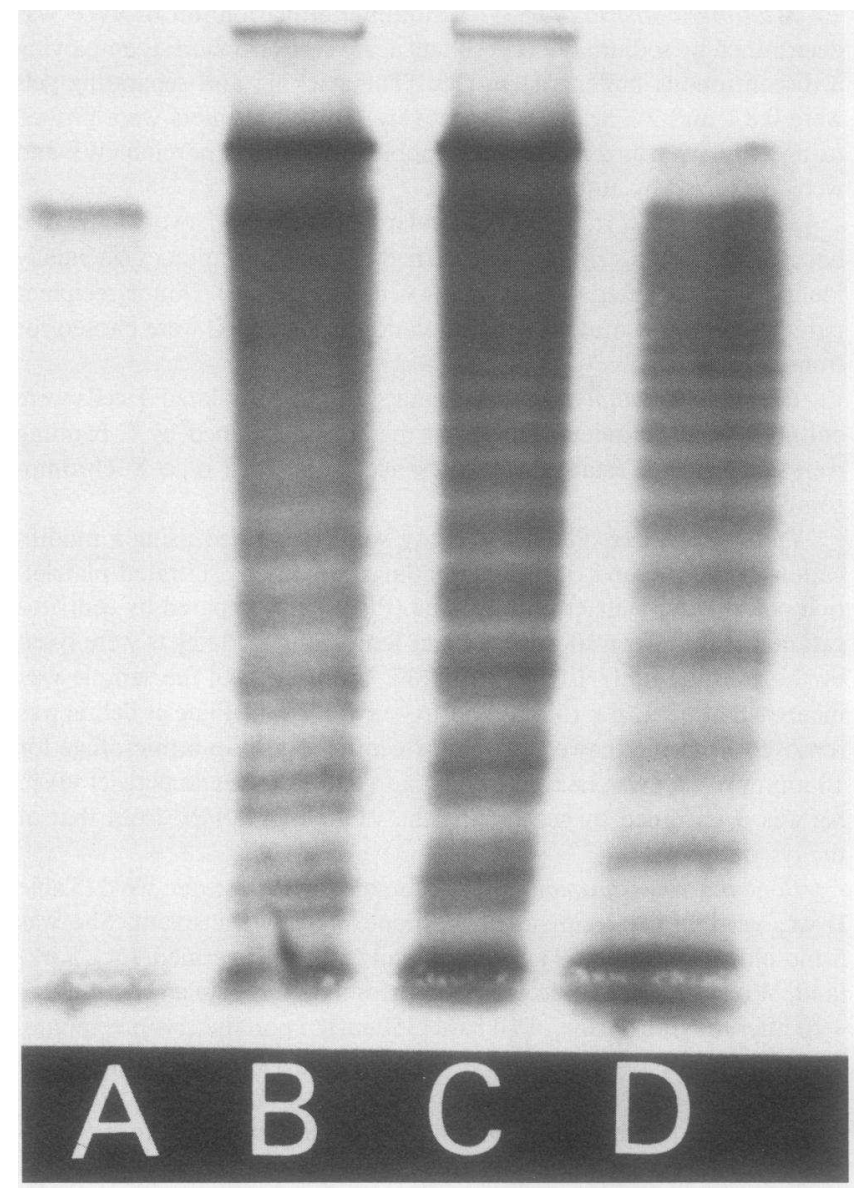

Figure 3. SDS gel electrophoresis of the vWF multimers. Lane $A$, plasma from the recipient pig 2 mo after transplantation. Lane $B$, platelets of the recipient pig after engraftment. Lane $C$, platelets of the donor pig. Lane $D$, plasma from the donor pig.

In the transplanted pig, which had vWF in the platelets, the bleeding time was shortened when the level of plasmatic vWF: $\mathrm{Ag}$ was raised to only $10 \mathrm{U}$ by transfusion of a partially purified preparation of vWF (Fig. 4). The transplanted pig was receiving

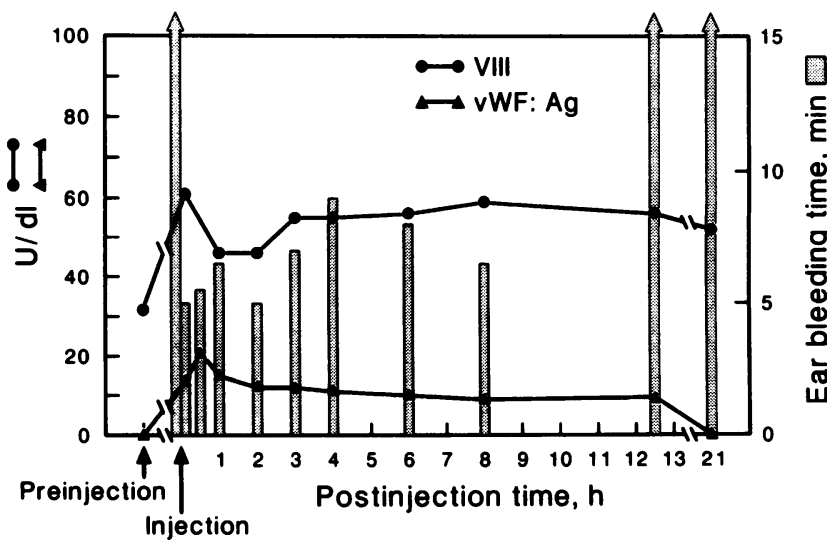

Figure 4. Intravenous injection of vWf. Shortening of the ear immersion bleeding time of the transplanted pig by the transfusion of enough partially purified porcine vWF to raise the circulating levels to $\sim 10 \mathrm{U} / \mathrm{dl}$. VWF is present in the platelets. The pig was receiving 40 $\mathrm{mg}$ of prednisone daily. 
$40 \mathrm{mg}$ of prednisone daily, and the control for this experiment was a von Willebrand pig that was also receiving $40 \mathrm{mg}$ prednisone. In the control pig (Fig. 5) the bleeding time remained abnormal (more than $30 \mathrm{~min}$ ) when the level of vWF:Ag was raised to $10 \mathrm{U} / \mathrm{dl}$.

Injection of $D D A V P$. A previous experiment in which DDAVP had been injected into a normal pig failed to produce an increase in the plasmatic level of vWF:Ag and RCoF. We repeated the experiment in the bone marrow-reconstituted pig to determine whether, given the initially lower levels, we could see an increase in these activities.

$21 \mu \mathrm{g}$ of DDAVP in $50 \mathrm{ml}$ of saline were injected intravenously into the transplanted pig (weight, $70 \mathrm{~kg}$ ) over a period of $30 \mathrm{~min}$. The values for vWF:Ag and RCoF were $<3 \mathrm{U} / \mathrm{dl}$ before the injection and remained unchanged $1 \mathrm{~h}$ after the injection.

A normal pig (weight, $97 \mathrm{~kg}$ ) was given $29.1 \mu \mathrm{g}$ of DDAVP in $50 \mathrm{ml}$ of saline over a period of $30 \mathrm{~min}$. Before the injection, the value for vWF:Ag was $94 \mathrm{U} / \mathrm{dl}$ and for $\mathrm{RCoF}$ was $56 \mathrm{U} / \mathrm{dl}$. $1 \mathrm{~h}$ after the injection the vWF:Ag was $92 \mathrm{U} / \mathrm{dl}$ and the RCoF was $62 \mathrm{U} / \mathrm{dl}$.

Clinical improvement in hemostasis. After engraftment the pig had four challenges to the hemostatic mechanism: (a) a laceration to the tongue; $(b)$ a laceration to the right upper lip measuring $1 \mathrm{~cm} ;(c)$ an accidental laceration to the lower leg which raised a skin flap measuring $5 \times 2 \mathrm{~cm}$; and $(d)$ the extraction of a loose upper incisor tooth.

The bleeding from all these lesions stopped spontaneously within $5 \mathrm{~min}$; whereas our past experience would have led us to expect prolonged bleeding in a pig with severe homozygous vWd (see Discussion).

\section{Discussion}

An animal model has been produced in which there is vWF in the platelet, minimal vWF in the plasma, and no vWF in the endothelial cell. This model enabled the role of platelet vWF in hemostasis to be investigated by means of the ear immersion bleeding time and the ratio bleeding time.

The results show that platelet vWF improves the hemostatic

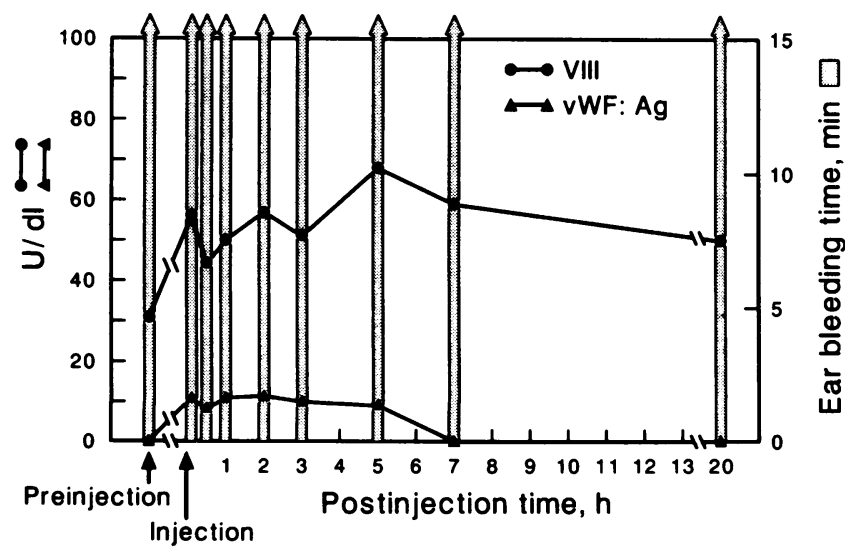

Figure 5. Intravenous injection of vWf. The transfusion of partially purified porcine vWF into a pig with severe vWd does not cause shortening of the bleeding time when the levels of circulating vWF are $\sim 10$ $\mathrm{U} / \mathrm{dl}$. The bleeding time was allowed to continue for $30 \mathrm{~min}$ before it was stopped by external pressure. The pig was receiving $40 \mathrm{mg}$ of prednisone daily. mechanism in severe vWd but does not make it normal. Studies in which vWF was transfused into the plasma of the transplanted pig showed that the presence of vWF in the platelet allowed hemostasis to occur at lower levels of plasmatic vWF than when vWF was absent from the platelet.

Perhaps the most striking evidence for improvement in hemostasis is a clinical one. The pig suffered four challenges to the hemostatic mechanism after the engraftment of the bone marrow (see Results). In a pig with severe vWd, these lesions probably would have bled for many hours. The leg laceration would have been expected to require repeated infusions of vWF over a period of several days. We were impressed by the rapidity with which the lesions stopped bleeding and felt that this was evidence of improvement in the hemostatic mechanism.

On the day after the tongue laceration the vWF:Ag measured $19 \mathrm{U} / \mathrm{dl}$. It is possible that this increase in the plasmatic level of vWF:Ag was due to its release from the platelets aggregating at the wound site. The level of vWF:Ag was not measured after the other hemostatic challenges.

The vWF:Ag and RCoF remained at low levels after the transplantation and were often undetectable by the Laurell assay. The plasmatic compartment, therefore, is only minimally replenished by the vWF in the platelet and megakaryocyte. The immunoradiometric assay gave higher values than the Laurell assay, which may reflect the fact that both assays have been standardized against normal plasmatic vWF:Ag. The plasmatic vWF:Ag in the transplanted pig could only come from the platelet or the megakaryocyte and, thus, it may differ from normal plasmatic vWF:Ag, resulting in a difference in the findings of the immunoradiometric and Laurell assays.

An attempt was made to assess the role of vWF released from the platelet in vivo by the intravenous administration of DDAVP (see Results). The administration of DDAVP, however, did not produce any rise in the level of plasmatic vWF in the transplanted animal or in a normal control.

Patients have been described with low levels of plasmatic vWF and normal levels in the platelet $(40,41)$. The patients have normal or almost normal bleeding times in contrast to the prolonged bleeding times found in patients with low levels of platelet vWF or abnormal platelet vWF; these findings in humans would also suggest that platelet vWF plays a role in the hemostatic mechanism.

The transplantation of bone marrow from normal or von Willebrand pigs allows the production of unusual models, so that the individual contributions of plasmatic, platelet, and endothelial cell vWF can be investigated.

\section{Acknowledgments}

We thank Dr. S. Breanndan Moore and Steven DeGoey for doing the mixed lymphocyte culture studies; Dr. Gordon Dewald, Judy Allen, and Richard Carlson for doing the cytogenetic studies; Dr. Richard Evans and Francis Weber for administering the radiation; Todd Daniels for the gels of the von Willebrand polymers; Donna Mujwid for the immunoradiometric assay of vWF and for the fluorescence studies of the platelets; Robert Sikkink for assisting in the platelet concentrate preparation; and Dorothy Suddendorf for her assistance in preparing the manuscript.

\section{References}

1. Van Mourik, J. A., B. N. Bouma, W. T. LaBruyere, S. deGraaf, and I. A. Mochtar. 1974. Factor VIII, a series of homologous oligomers and a complex of two proteins. Thromb. Res. 4:155-164. 
2. Fass, D. N., G. J. Knutson, and E. J. W. Bowie. 1978. Porcine Willebrand factor: a population of multimers. J. Lab. Clin. Med. 91: 307-320.

3. Counts, R. B., S. L. Paskell, and S. K. Elgee. 1978. Disulfide bonds and the quaternary structure of Factor VIII/von Willebrand factor. $J$. Clin. Invest. 62:702-709.

4. Ruggeri, Z. M., and T. S. Zimmerman. 1980. Variant von Willebrand's disease. Characterization of two subtypes by analysis of multimeric composition of Factor VIII/von Willebrand factor in plasma and platelets. J. Clin. Invest. 65:1318-1325.

5. Wall, R. T., R. B. Counts, L. A. Harker, and G. E. Striker. 1980. Binding and release of Factor VIII/von Willebrand factor by human endothelial cells. Br. J. Haematol. 46:287-298.

6. Rand, J. H., R. E. Gordon, I. I. Sussman, S. V. Chu, and V. Solomon. 1980. Electron microscopic localization of Factor VIII-related antigen in human blood vessels. Circulation. 62:III-169. (Abstr.)

7. Jaffe, E. A., L. W. Hoyer, and R. L. Nachman. 1973. Synthesis of antihemophilic factor antigen by cultured human endothelial cells. $J$. Clin. Invest. 62:2757-2764.

8. Jaffe, E. A., L. W. Hoyer, and R. L. Nachman. 1974. Synthesis of von Willebrand factor by cultured human endothelial cells. Proc. Natl. Acad. Sci. USA. 71:1906-1909.

9. Tuddenham, E. G. D., J. Lazarchick, and L. W. Hoyer. 1981. Synthesis and release of Factor VIII by cultured human endothelial cells. Br. J. Haematol. 47:617-626.

10. Nachman, R., R. Levine, and E. A. Jaffe. 1977. Synthesis of Factor VIII-antigen by cultured guinea pig megakaryocytes. J. Clin. Invest. 60:914-921.

11. Kimura, A., E. J. W. Bowie, R. J. Campbell, and D. N. Fass. 1979. Willebrand factor in hemostasis in the in vitro bleeding time. Blood. 54:1347-1357.

12. Bowie, E. J. W., D. N. Fass, and C. A. Owen, Jr. 1980. Hemostatic effect of transfused Willebrand factor in porcine von Willebrand's disease. Similarities to the human disease. Haemostasis. 9:351-365.

13. Nachman, R. L., and E. A. Jaffe. 1975. Subcellular platelet Factor VIII antigen and von Willebrand factor. J. Exp. Med. 141:1101-1113.

14. Slot, J. W., B. N. Bouma, R. Montgomery, and T. S. Zimmerman. 1978. Platelet Factor VIII-related antigen: immunofluorescent localization. Thromb. Res. 13:871-881.

15. Zucker, M. B., M. J. Broekman, and K. L. Kaplan. 1979. Factor VIII-related antigen in human blood platelets: localization and release by thrombin and collagen. J. Lab. Clin. Med. 94:675-682.

16. Sultan, Y., P. Maisonneuve, and E. Angeles-Cano. 1979. Release of VIIIR:Ag and VIIIR:WF during thrombin and collagen-induced aggregation. Thromb. Res. 15:415-425.

17. Koutts, J., P. N. Walsh, E. F. Plow, J. W. Fenton, II, B. N. Bouma, and T. S. Zimmerman. 1978. Active release of human platelet Factor VIII-related antigen by adenosine diphosphate, collagen, and thrombin. J. Clin. Invest. 62:1255-1263.

18. Fernandez, M. F. L., M. H. Ginsberg, Z. M. Ruggeri, F. J. Battle, and T. S. Zimmerman. 1982. Multimeric structure of platelet Factor VIII/von Willebrand factor: the presence of large multimers and their reassociation with thrombin-stimulated platelets. Blood. 60:1132-1138.

19. Bowie, E. J. W., C. A. Owen, Jr., P. E. Zollman, J. H. Thompson, Jr., and D. N. Fass. 1973. Tests of hemostasis in swine: normal values and values in pigs affected with von Willebrand's disease. Am. J. Vet. Res. 34:1405-1407.

20. Bowie, E. J. W., and C. A. Owen, Jr. 1979. Von Willebrand's disease. In CRC Handbook Series in Clinical Laboratory Science, Section I: Hematology, Vol. I. CRC Press Inc., Boca Raton, FL. 471-501.

21. Mannucci, P. M., F. I. Pareti, L. Holmberg, I. M. Nilsson, and Z. M. Ruggeri. 1976. Studies on the prolonged bleeding time in von Willebrand's disease. J. Lab. Clin. Med. 88:662-671.

22. Fass, D. N., W. J. Brockway, C. A. Owen, Jr., and E. J. W. Bowie. 1976. Factor VIII (Willebrand) antigen and ristocetin-Willebrand factor in pigs with von Willebrand's disease. Thromb. Res. 8:319-327.

23. Fass, D. N., E. J. W. Bowie, C. A. Owen, Jr., and P. E. Zollman.
1979. Inheritance of porcine von Willebrand's disease: study of a kindred of over 700 pigs. Blood. 53:712-719.

24. Griggs, T. R., W. P. Webster, H. A. Cooper, R. H. Wagner, and K. M. Brinkhous. 1974. Von Willebrand factor: gene dosage relationships and transfusion response in bleeder swine-a new bioassay. Proc. Natl. Acad. Sci. USA. 71:2087-2090.

25. Bowie, E. J. W., J. H. Thompson, Jr., P. Didisheim, and C. A Owen, Jr. 1971. Mayo Clinic Laboratory Manual of Hemostasis. W. B. Saunders Co., Philadelphia. 1-186.

26. Olson, J. D., W. J. Brockway, D. N. Fass, M. A. Magnuson, and E. J. W. Bowie. 1975. Evaluation of ristocetin-Willebrand factor assay and ristocetin-induced platelet aggregation. Am. J. Clin. Pathol. 63:210218.

27. Laurell, C. B. 1966. Quantitative estimation of proteins by electrophoresis in agarose gel containing antibodies. Anal. Biochem. 15:4552.

28. Katzmann, J. A., D. K. Mujwid, R. S. Miller, and D. N. Fass. 1981. Monoclonal antibodies to von Willebrand factor: reactivity with porcine and human. Blood. 58:530-536.

29. Olson, J. D., W. J. Brockway, D. N. Fass, E. J. W. Bowie, and K. G. Mann. 1977. Purification of porcine and human ristocetin-Willebrand factor. J. Lab. Clin. Med. 89:1278-1294.

30. Weiss, H. J., L. W. Hoyer, F. R. Rickles, A. Varma, and J. Rogers. 1973. Quantitative assay of a plasma factor deficient in von Willebrand's disease that is necessary for platelet aggregation. J. Clin. Invest. 52:27082716.

31. Mertz, E. T. 1942. The anomaly of a normal Duke's and a very prolonged saline bleeding time in swine suffering from an inherited bleeding disease. Am. J. Physiol. 136:360-362.

32. Doettl, K., and O. Ripke. 1938. Blutgerinnung und Blutungszeit. In Medizin und Chemie. Leverkusen, Bayer, Federal Republic of Germany. 267-273.

33. Ruggeri, Z. M., and T. S. Zimmerman. 1981. The complex multimeric composition of Factor VIII/von Willebrand factor. Blood. 57: $1140-1143$

34. Bach, F. H., E. Day, M. L. Bach, B. A. Myhre, D. P. S. Sengar, and P. I. Terasaki. 1971. Histocompatibility matching. V. Comparison of typing and mixed cultures in unrelated individuals. Tissue Antigens. 1:39-46.

35. Yamamura, M., B. Nikbin, and J. R. Hobbs. 1976. Standardisation of the mixed lymphocyte reaction. J. Immunol. Methods. 10:367378 .

36. Pineda, A. A., S. B. Moore, J. E. Woods, K. P. Offord, H. Zincke, and H. F. Taswell. 1980. Mixed lymphocyte culture, phytohemagglutinin stimulation, and matching grade: clinical relevance in renal transplantation from living related donors. Transplantation (Baltimore). 29:9799.

37. Rudek, Z., and L. Kwiatkowska. 1983. Possibility of detecting fetal lymphocytes in the maternal blood of the domestic pig, Sus scrofa. Cytogenet. Cell Genet. 36:580-583.

38. Gralnick, H. R., S. B. Williams, L. P. McKeown, D. M. Krizek, B. C. Shafer, and M. E. Rick. 1985. Platelet von Willebrand factor: comparison with plasma von Willebrand factor. Thromb. Res. 38:623633.

39. Slichter, S. J., R. B. Counts, R. Henderson, and L. A. Harker. 1976. Preparation of cryoprecipitated factor VIII concentrates. Transfusion (Phila.). 16:616-626.

40. Weiss, H. J., G. Pietu, R. Rabinowitz, J.-P. Girma, J. Rogers, and D. Meyer. 1983. Heterogenous abnormalities in the multimeric structure, antigenic properties, and plasma-platelet content of Factor VIII/von Willebrand factor in subtypes of classic (type I) and variant (type IIA) von Willebrand's disease. J. Lab. Clin. Med. 101:411-425.

41. Mannucci, P. M., R. Lombardi, R. Bader, L. Vianello, A. B. Frederici, S. Solinas, M. G. Mazzucconi, and G. Mariani. 1985. Heterogeneity of type I von Willebrand disease: evidence for a subgroup with an abnormal von Willebrand factor. Blood. 66:796-802. 